\title{
Downregulation of 265 proteasome catalytic activity promotes epithelial-mesenchymal transition
}

\author{
Asoka Banno ${ }^{1, *}$, Daniel A. Garcia ${ }^{1,}{ }^{*}$, Eric D. van Baarsel ${ }^{1}$, Patrick J. Metz ${ }^{1}$, Kathleen \\ Fisch $^{2}$, Christella E. Widjaja ${ }^{1}$, Stephanie H. Kim ${ }^{1}$, Justine Lopez ${ }^{1}$, Aaron N. Chang ${ }^{2}$, \\ Paul P. Geurink ${ }^{4}$, Bogdan I. Florea ${ }^{3}$, Hermen S. Overkleeft ${ }^{3}$, Huib Ovaa ${ }^{4}$, Jack D. \\ Buil $^{5}$, Jing Yang ${ }^{6,7,8}$ and John T. Chang ${ }^{1}$ \\ ${ }^{1}$ Department of Medicine, University of California San Diego, La Jolla, CA, USA \\ ${ }^{2}$ Center for Computational Biology and Bioinformatics, Institute for Genomic Medicine, University of California San Diego, \\ La Jolla, CA, USA \\ ${ }^{3}$ Division of Chemical Biology, Leiden Institute of Chemistry, Leiden University, Gorlaeus Laboratories, Leiden, The Netherlands \\ ${ }^{4}$ Division of Cell Biology, The Netherlands Cancer Institute, Amsterdam, The Netherlands \\ ${ }^{5}$ Department of Pathology, University of California San Diego, La Jolla, CA, USA \\ ${ }^{6}$ Department of Pharmacology, University of California San Diego, La Jolla, CA, USA \\ 7 Department of Pediatrics, University of California San Diego, La Jolla, CA, USA \\ ${ }^{8}$ Moores Cancer Center, University of California San Diego, La Jolla, CA, USA \\ * These authors have contributed equally to this article \\ Correspondence to: John T. Chang, email: changj@ucsd.edu
}

Keywords: EMT, proteasome, TGF-beta, cancer stem cells

Received: October 10,2015 Accepted: January 24, $2016 \quad$ Published: February 22, 2016

\section{ABSTRACT}

The epithelial-mesenchymal transition (EMT) endows carcinoma cells with phenotypic plasticity that can facilitate the formation of cancer stem cells (CSCs) and contribute to the metastatic cascade. While there is substantial support for the role of EMT in driving cancer cell dissemination, less is known about the intracellular molecular mechanisms that govern formation of CSCs via EMT. Here we show that $\beta 2$ and $\beta 5$ proteasome subunit activity is downregulated during EMT in immortalized human mammary epithelial cells. Moreover, selective proteasome inhibition enabled mammary epithelial cells to acquire certain morphologic and functional characteristics reminiscent of cancer stem cells, including CD44 expression, self-renewal, and tumor formation. Transcriptomic analyses suggested that proteasome-inhibited cells share gene expression signatures with cells that have undergone EMT, in part, through modulation of the TGF- $\beta$ signaling pathway. These findings suggest that selective downregulation of proteasome activity in mammary epithelial cells can initiate the EMT program and acquisition of a cancer stem cell-like phenotype. As proteasome inhibitors become increasingly used in cancer treatment, our findings highlight a potential risk of these therapeutic strategies and suggest a possible mechanism by which carcinoma cells may escape from proteasome inhibitor-based therapy.

\section{INTRODUCTION}

Cancer is one of the leading causes of death in the United States, and up to $90 \%$ of cancer-associated mortality can be attributed to therapy-resistant metastatic disease [1]. During the metastatic cascade, tumor cells gain the capacity to invade locally and disseminate into the vasculature. However, not all cells that enter the vasculature go on to colonize distant sites. Only a small subset of invading tumor cells acquire characteristics of cancer stem cells (CSCs) needed to establish macrometastases, namely self-renewal capacity, proliferative potential, and chemoresistance [2]. There is increasing evidence to support the involvement of CSCs in multiple types of hematologic and solid tumors, including breast, brain, prostate, colon, liver, and pancreatic, among 
others [3]. Although the ontogeny of CSCs is incompletely understood, a developmental process known as the epithelial-mesenchymal transition (EMT) has been shown to promote the development of cells with CSC properties [4-8]. Previous studies have identified the transcription factors TWIST1, SNAI1, and ZEB1 as key inducers of EMT, metastasis, and the CSC phenotype [3, 6, 8-10]. Thus, identifying the factors that regulate EMT is highly relevant to cancer therapy as these stimuli can be targeted to block metastasis, and potentially CSC formation, in carcinomas.

Recent evidence suggests that CSCs may exhibit decreased proteasome activity [11-15]. The 26S proteasome is comprised of a $20 \mathrm{~S}$ core complex that contains $\beta 1, \beta 2$, and $\beta 5$ catalytic subunits that contain caspase-like, trypsin-like, and chymotrypsin-like proteolytic sites, respectively [16, 17]. The observation of decreased proteasome activity in CSCs led us to hypothesize that downregulation of proteasome activity might be causally related to the acquisition of the CSC phenotype, via EMT.

Here we show that immortalized human mammary epithelial (HMLE) cells and MCF10A cells, both wellestablished model systems for EMT [6], decrease their proteasome activity as they undergo EMT. Strikingly, we observed that selective inhibition of $\beta 2$ or $\beta 5$ subunit proteasome activity was sufficient to induce HMLE and MCF10A cells to acquire key morphologic and functional characteristics of the EMT. Transcriptomic analyses suggested that proteasome-inhibited cells share gene expression signatures with cells that had undergone EMT, in part, through modulation of the TGF- $\beta$ signaling pathway. Taken together, these data suggest that downregulation of proteasome activity in breast cancer cells can initiate the EMT program, thereby conferring upon these cells key attributes of CSCs.

\section{RESULTS}

\section{Downregulation of proteasome activity is associated with EMT}

We first sought to determine whether cells undergoing EMT alter their levels of proteasome activity. We utilized HMLE cells in which EMT can be induced by stable overexpression of SNAI1 or TWIST1, or by treatment with TGF- $\beta 1$ (hereafter referred to as HMLESnail, HMLE-Twist, or HMLE+TGF- $\beta 1$, respectively), as previously described $[6,18-22]$. We determined proteasome activity by using subunit-specific probes that bind irreversibly to the $\beta 1, \beta 2$, or $\beta 5$ proteasome catalytic subunits (Supplementary Figure S1) [2325]. We observed that cells that had undergone EMT exhibited a $25-30 \%$ reduction in $\beta 2$ and $\beta 5$, but not $\beta 1$, subunit activity compared to cells that had not undergone EMT (Figure 1A, 1B). This is likely due to a reduction in specific proteasome activity, since total protein and mRNA expression of these subunits remained unaffected by EMT induction (Supplementary Figure S2A and S2B). In support of this finding, we observed that cells that had undergone EMT also exhibited an accumulation of ubiquitinated proteins, compared to their epithelial parental cells (Figure 1C). Taken together, these data suggest that HMLE cells decrease specific proteasome catalytic activities - not proteasome amounts - during EMT.

\section{Selective inhibition of proteasome activity induces the EMT phenotype}

To investigate whether the reduction in proteasome activity is mechanistically linked to the process of EMT, we treated HMLE cells with selective $\beta 1, \beta 2$, or $\beta 5$ proteasome subunit inhibitors (Supplementary Figure S1) [25-27]. We then assessed the cell surface expression of CD44 by HMLE cells after 14 days of treatment. High expression of CD44 has been associated with human breast cancer stem cells $[28,29]$ as well as with HMLE cells that have undergone EMT [6]. Strikingly, 98\% of cells treated with $\beta 2$ subunit inhibitor and $57 \%$ of those treated with $\beta 5$ subunit inhibitor expressed high levels of CD44, compared to $12 \%$ of DMSO-treated cells (Figure $2 \mathrm{~A})$. By contrast, cells treated with the $\beta 1$ subunit inhibitor expressed low levels of CD44 (Figure 2A), consistent with the lack of change in $\beta 1$ subunit proteasome activity within cells that had undergone EMT (Figure 1A, 1B). To exclude the possibility that the increase of the CD $44^{\text {high }}$ population was due to selective outgrowth of CD44 ${ }^{\text {high }}$ cells, HMLE cells were first FACS sort-purified for low expression of CD44, then treated with selective proteasome inhibitors (Supplementary Figure S3A). We found that CD44 ${ }^{\text {low }}$ cells treated with proteasome inhibitors gave rise to CD44 ${ }^{\text {high }}$ cells after 14 days of treatment (Supplementary Figure $\mathrm{S} 3 \mathrm{~B}$ ), demonstrating that these cells arose directly from CD44 ${ }^{\text {low }}$ cells.

CD44 ${ }^{\text {high }}$ cells that emerged after treatment with selective $\beta 2$ or $\beta 5$ subunit inhibitors lost their cobblestonelike appearance and acquired the fibroblast-like morphology characteristic of mesenchymal cells (Figure 2B). Moreover, cells treated with selective proteasome inhibitors decreased their expression of epithelial marker E-cadherin and increased their expression of mesenchymal markers fibronectin and vimentin, as shown by immunofluorescence and immunoblot analyses (Figure $2 \mathrm{C}, 2 \mathrm{D})$. Together, these results suggest that selective $\beta 2$ or $\beta 5$ subunit inhibition induces HMLE cells to acquire an EMT phenotype.

In addition to exhibiting mesenchymal characteristics, we found that cells with lower levels of 
proteasome activity exhibited decreased apoptosis, in comparison to parental HMLE cells, when treated with the pan-proteasome inhibitor epoxomicin (Figure 2E). These results suggest that the reduced level of proteasome activity associated with EMT confers increased resistance to the cytotoxic effects of pan-proteasome inhibition. Furthermore, these results are consistent with prior observations that CSCs may be more resistant to proteasome inhibitors [14].

We found that a second non-tumorigenic human mammary epithelial cell line, MCF10A, also downregulated $\beta 2$ and $\beta 5$ subunit activity while undergoing EMT in response to TGF- $\beta 1$ (Supplementary Figure S4A). MCF10A cells have been previously shown to decrease their expression of CD24 as they undergo EMT [7]. We observed a decrease in CD24 expression in MCF10A cells treated with selective $\beta 2$ or $\beta 5$ subunit inhibitors, suggesting that these cells had undergone EMT (Supplementary Figure S4B). In addition, MCF10A cells treated with $\beta 2$ or $\beta 5$ subunit inhibitors exhibited a fibroblast-like morphology, decreased expression of epithelial markers, and increased expression of mesenchymal markers at the protein and mRNA levels (Supplementary Figure S4C-F). Together, these results suggest that induction of the EMT phenotype as a result of selective $\beta 2$ or $\beta 5$ inhibition of proteasome activity may be a generalizable phenomenon.

\section{Cells treated with selective proteasome inhibitors acquire the ability to self-renew}

We next sought to confirm that the CD44 $4^{\text {high }}$ cells that had arisen following treatment with proteasome inhibitors
A

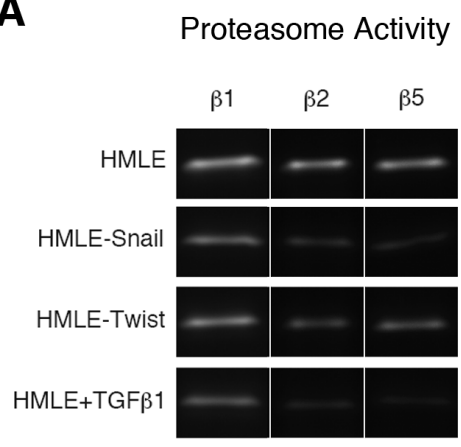

B

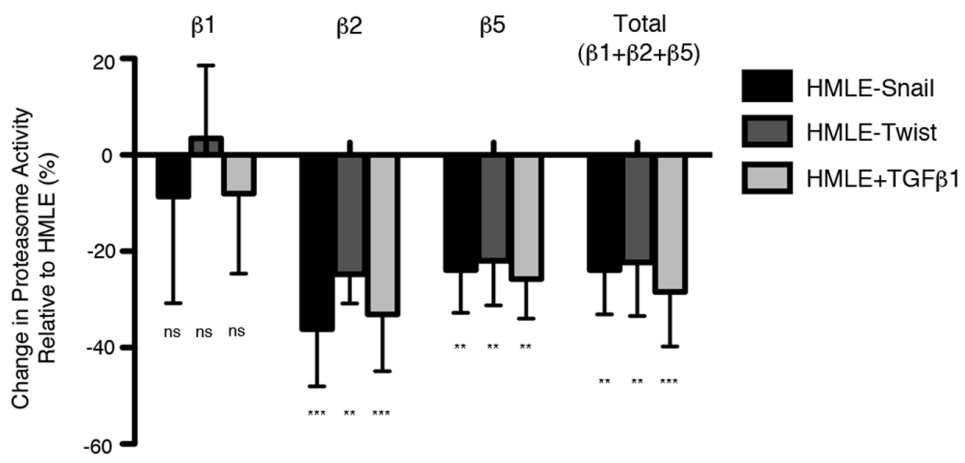

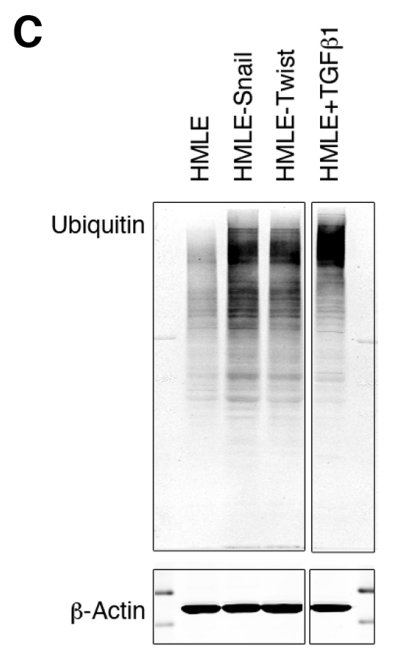

Figure 1: Downregulation of proteasome activity is associated with EMT. A. $\beta 1, \beta 2$, and $\beta 5$ subunit proteasome activity in HMLE, HMLE-Snail, HMLE-Twist, and HMLE+TGF- $\beta 1$ were measured by in-gel proteasome activity assay. Representative images of the SDS-PAGE gels are shown. Vertical spaces inserted between lanes indicate removal of intervening, irrelevant samples. All the samples were run on the same gel and imaged in a single scan. B. Quantification of $\beta 1, \beta 2$, and $\beta 5$ subunit activity as well as total catalytic activity (the sum of the three subunits) presented as percent change relative to HMLE. Error bars indicate standard error of the mean (SEM) ( $n \geq$ 3). C. Immunoblot of whole cell lysates from HMLE cells using an anti-ubiquitin antibody, representative of 3 independent experiments. $\beta$-actin served as a loading control. Vertical spaces inserted between lanes indicate removal of intervening, irrelevant samples. All the samples were run on the same gel, transferred and blotted together, and imaged in a single scan. 
A

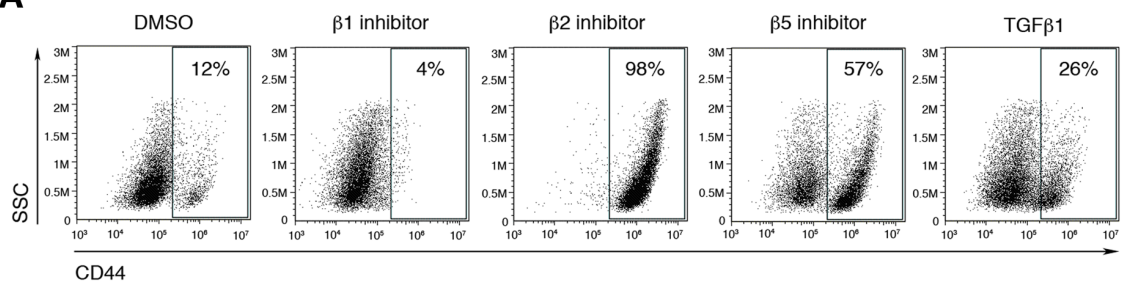

B

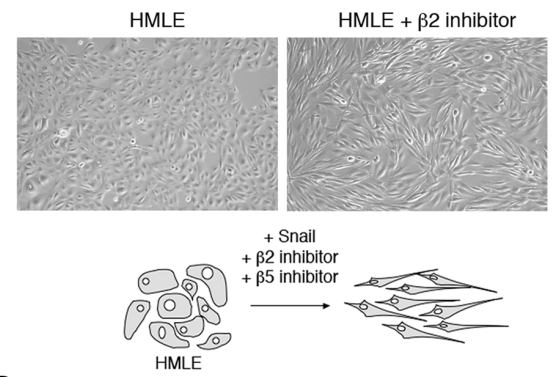

C

DAPI
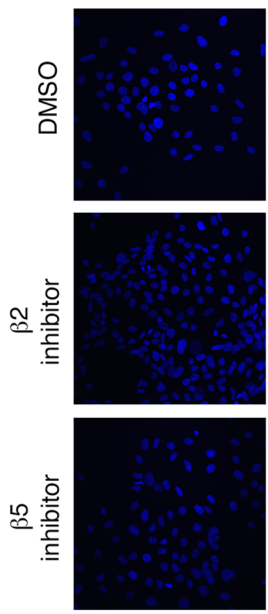

D

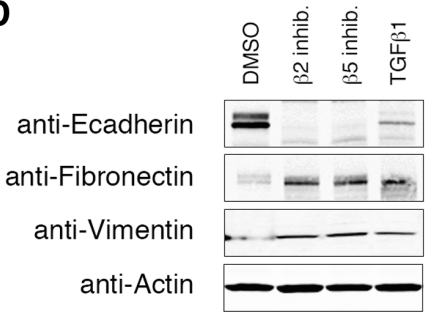

E-cadherin
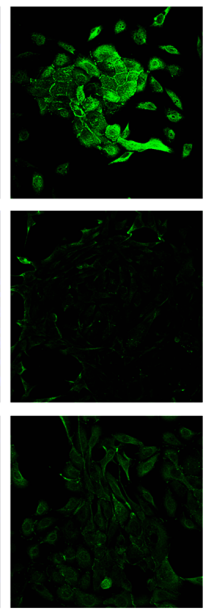
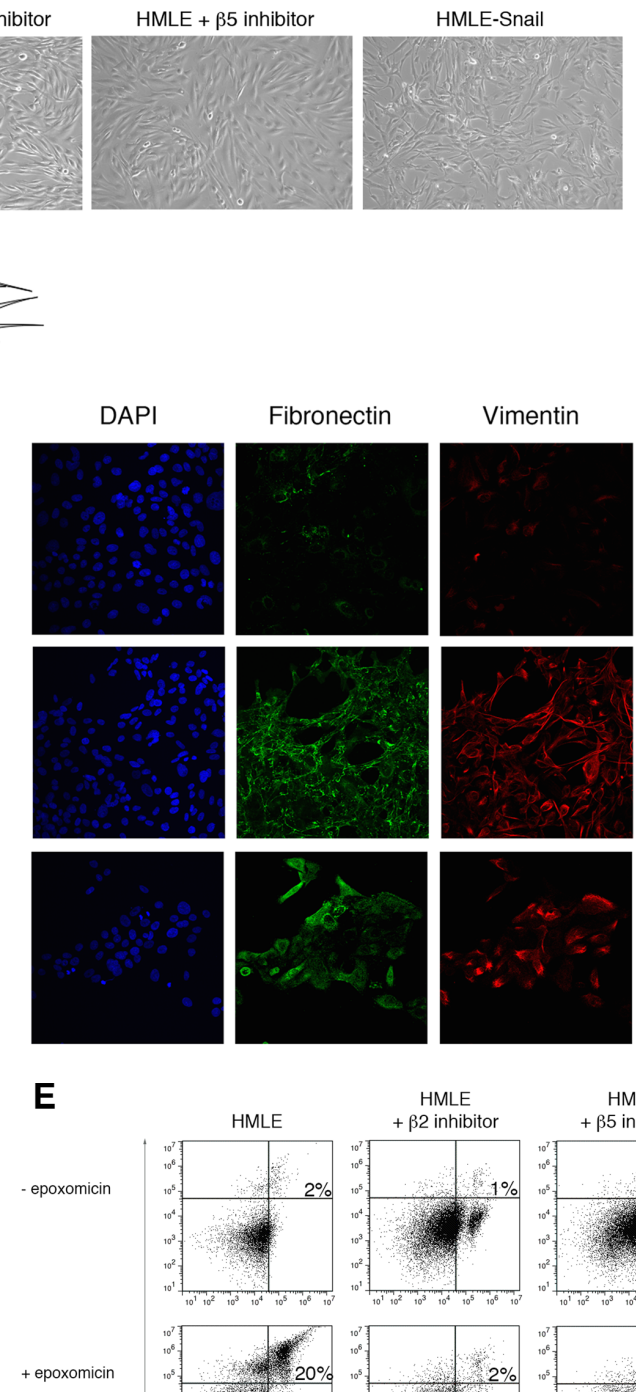

E
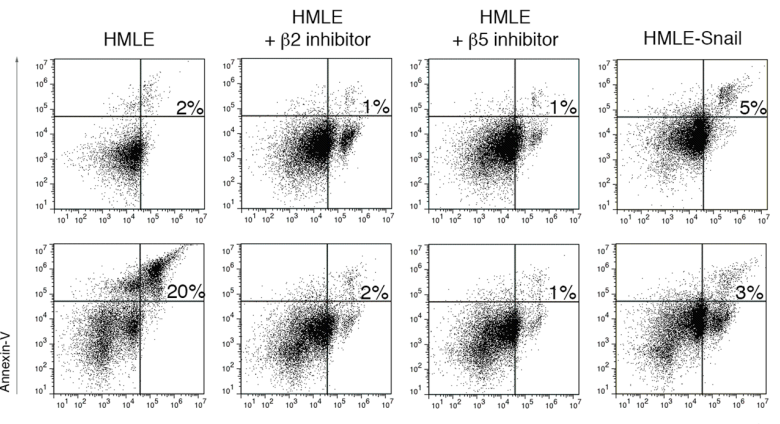

Figure 2: Selective inhibition of proteasome activity induces an EMT phenotype. A. Flow cytometry analysis of CD44 surface expression and side scatter (SSC) after 14 days of treatment with DMSO or $\beta 1, \beta 2$, or $\beta 5$ subunit inhibitor. Percentage of CD44 $4^{\text {high }}$ cells within the live population is indicated. Representative result of three independent experiments is shown. B. Representative brightfield images of HMLE, HMLE $+\beta 2$ inhibitor, HMLE $+\beta 5$ inhibitor, and HMLE-Snail after 14 days of treatment. All the images were taken at 10X magnification. Schematic diagram depicts the change in cell morphology during EMT. C. Confocal microscopy of E-cadherin (left panel; green), fibronectin (right panel; green), or vimentin (red) in HMLE cells treated with $\beta 2$ subunit inhibitor or $\beta 5$ subunit inhibitor for 14 days. Images were taken at $40 \mathrm{X}$ magnification. D. Immunoblot of whole cell lysates from HMLE, HMLE+ $\beta 2$ inhibitor, HMLE+ $\beta 5$ inhibitor, or HMLE+TGF- $\beta 1$ using anti-E-cadherin, anti-fibronectin, and anti-vimentin antibodies, representative of 3 independent experiments. $\beta$-actin served as a loading control. E. Flow cytometric analysis of 7-AAD and Annexin-V expression in HMLE, HMLE+ $\beta 2$ inhibitor, HMLE $+\beta 5$ inhibitor, and HMLE-Snail with or without 1 day of epoxomicin treatment. Percentage of $7-\mathrm{AAD}^{+} / \mathrm{AnnexinV}^{+}$cells is indicated. Representative result of three independent experiments is shown. 


\section{A}

HMLE

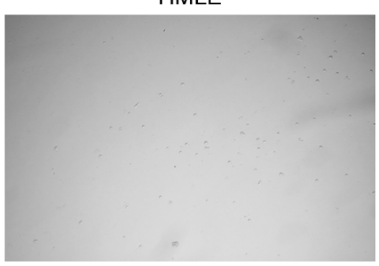

B

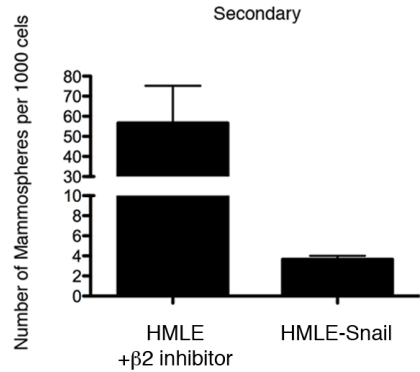

C

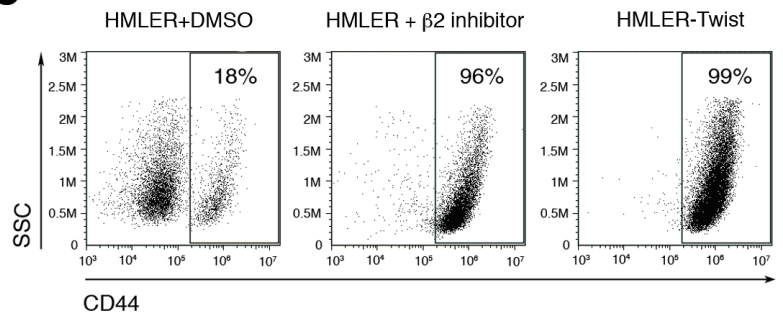

E
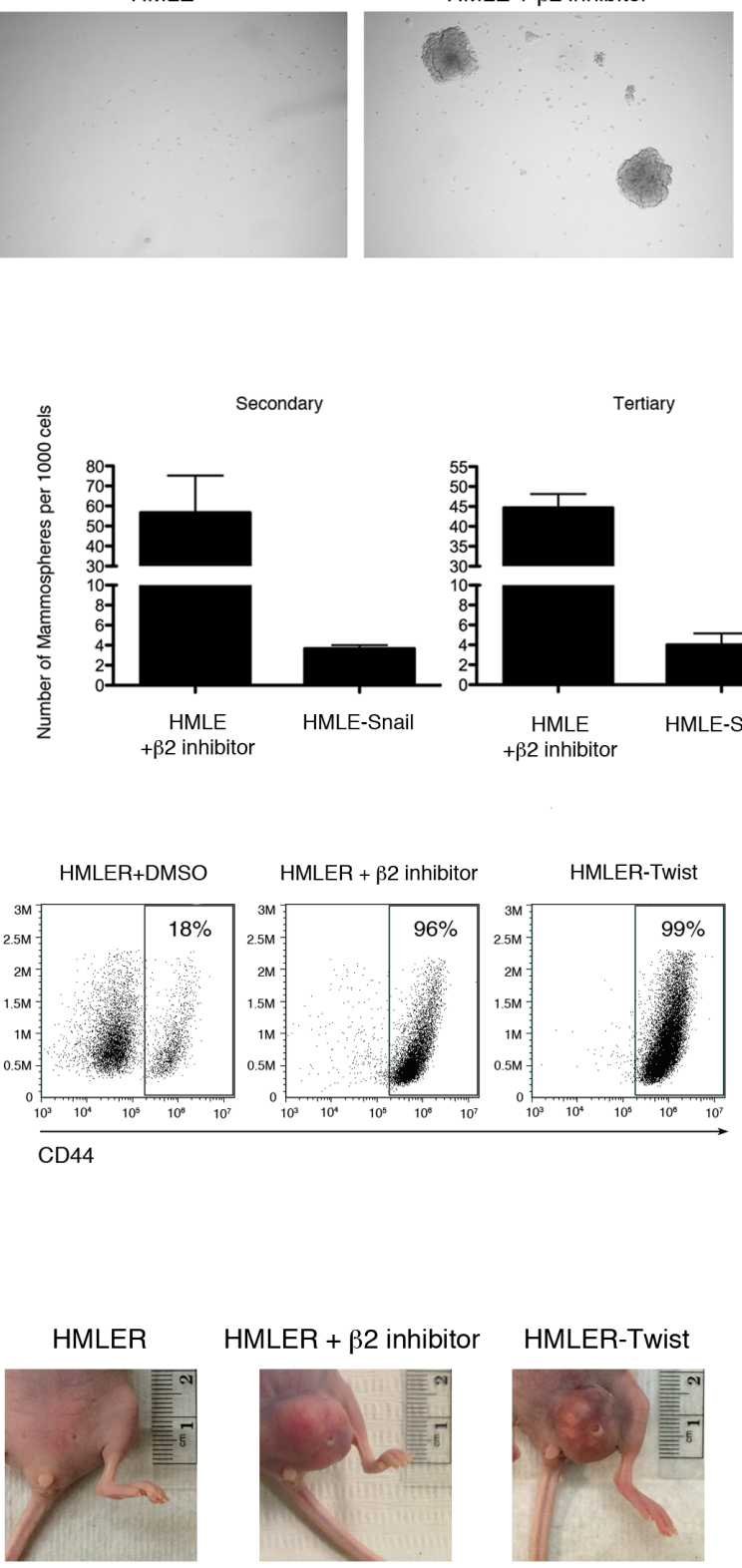

HMLE + $\beta 2$ inhibitor

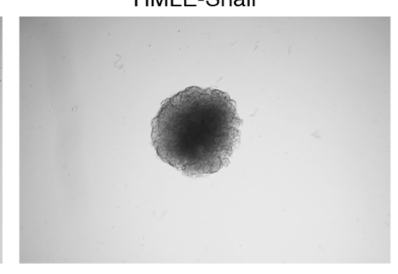

ertiary

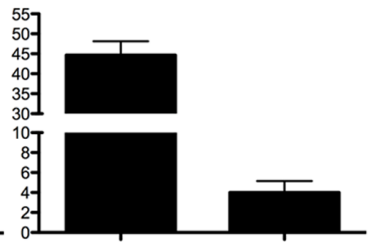

HMLE $+\beta 2$ inhibitor

HMLE-Snail

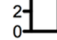

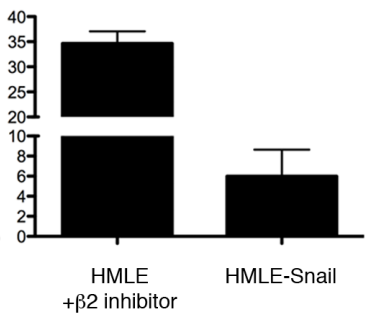

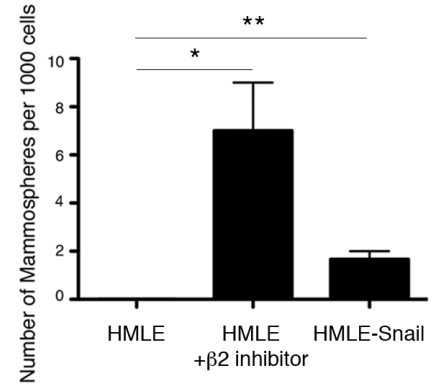

Quarternary

D
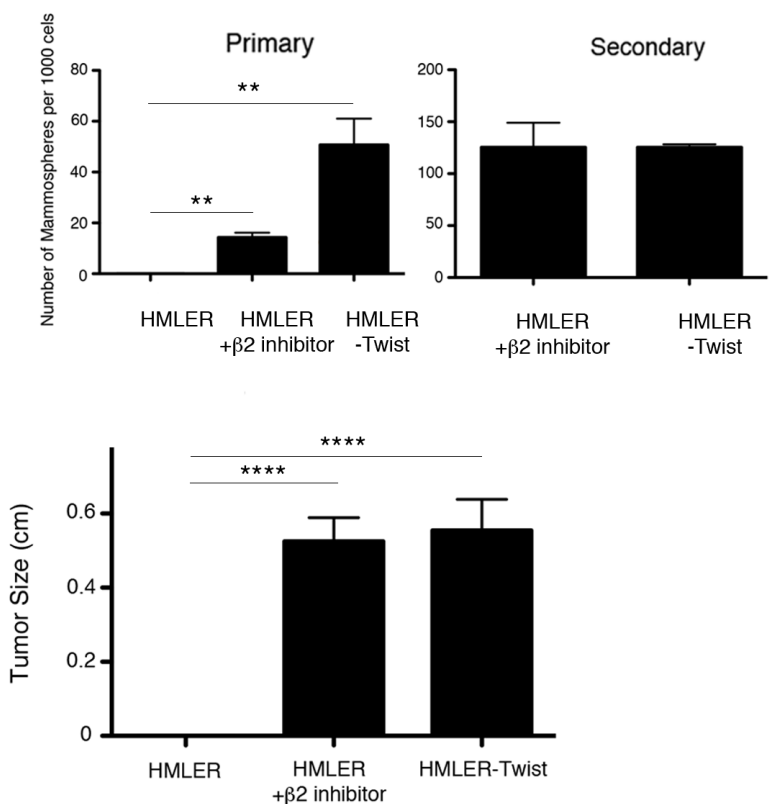

Figure 3: Selective inhibition of proteasome activity endows HMLE cells with self-renewal ability in vitro and tumorinitiating capacity in vivo. A. Quantification of primary mammospheres per 1000 seeded cells formed by HMLE, HMLE $+\beta 2$ inhibitor, or HMLE-Snail. Error bars indicate SEM $(n \geq 3)$. B. Serial passage of mammospheres. Quantification is presented in the bar graph as the number of mammospheres formed per 1000 seeded cells. Error bars indicate SEM ( $n$ 3). C. Flow cytometric analysis of CD44 expression by HMLER-Twist, $\beta 2$ subunit inhibitor-treated or DMSO-treated HMLER cells. Percentage of CD44 high cells within the live population is indicated. Representative result of three independent experiments is shown. D. Quantification of primary and secondary mammospheres formed by HMLER, HMLER+ $\beta 2$ inhibitor, or HMLER-Twist, presented in the bar graph as the number of mammospheres formed per 1000 seeded cells. Error bars indicate SEM $(n \geq 3)$. E. Primary tumor formation in immunodeficient mice 2 months after injection with HMLER, HMLER $+\beta 2$ inhibitor, or HMLER-Twist cells. Error bars indicate SEM ( $n=12$ mice per group). Representative images of the tumors are also shown. 
had indeed undergone EMT. We focused our studies on $\beta 2$ subunit inhibition due to its more pronounced effect (Figure 2A). It has been previously demonstrated that HMLE cells that have undergone EMT exhibit an increased ability to self-renew, a characteristic typically associated with mammary epithelial stem cells [6, 30, 31]. We therefore tested the ability of HMLE cells treated with proteasome inhibitors to form mammospheres, a capability indicative of self-renewal activity. Indeed, $\beta 2$ subunit inhibitor-treated HMLE cells acquired an enhanced capacity to form mammospheres compared to DMSO-treated cells, both in primary assays and during subsequent serial passages (Figure 3A, 3B). These results suggest that selective proteasome inhibition confers selfrenewal capabilities to HMLE cells.

\section{Selective inhibition of proteasome activity endows HMLER cells with tumor-initiating capacity in vivo}

We next wished to determine whether selective proteasome inhibition also endowed HMLE cells with the ability to initiate tumors, another property of CSCs. Accordingly, we used a tumor xenograft system in which HMLE cells constitutively expressing $R A S-V 12 H$ oncogene and TWIST1 (HMLER-Twist) renders them tumorigenic when injected into immunodeficient mice [32]. Similar to the behavior of proteasome-inhibited HMLE cells described above, HMLER cells treated with $\beta 2$ subunit inhibitor acquired a CD44 $4^{\text {high }}$ phenotype and the ability to form mammospheres (Figure 3C, 3D). To test the tumorigenic potential of these cells, we injected HMLER, HMLER-Twist, or $\beta 2$ subunit inhibitor-treated HMLER cells into immunodeficient mice. $92 \%$ of mice injected with HMLER-Twist or $\beta 2$ inhibitor-treated HMLER cells developed tumors with a mean size of $0.5 \mathrm{~cm}$; in contrast, mice injected with DMSO-treated HMLER cells did not develop tumors (Figure 3E). Taken together, these results suggest that downregulation of proteasome activity in HMLER cells can induce EMT and confer self-renewal and tumor-initiating capabilities, which are hallmarks of CSCs.

\section{Low proteasome subunit expression is associated with human breast cancer and decreased patient survival}

To determine whether the link between reduced proteasome activity and tumorigenicity might apply to human patients with breast carcinoma, we analyzed publicly available gene expression data from the Oncomine Platform and The Cancer Genome Atlas. Intriguingly, we found that tumor samples from patients with invasive breast carcinoma exhibited significantly lower PSMB2 and PSMB5 proteasome subunit mRNA expression compared to samples derived from normal tissue (Figure 4A). Moreover, breast cancer patients with tumors exhibiting the lowest quartile of PSMB2 and PSMB5 combined mRNA expression showed reduced 5-year survival compared to patients with tumors in the highest quartile (Figure 4B). Together, these data suggest that low proteasome subunit expression may be useful as an indicator of poor prognosis for breast cancer patients.
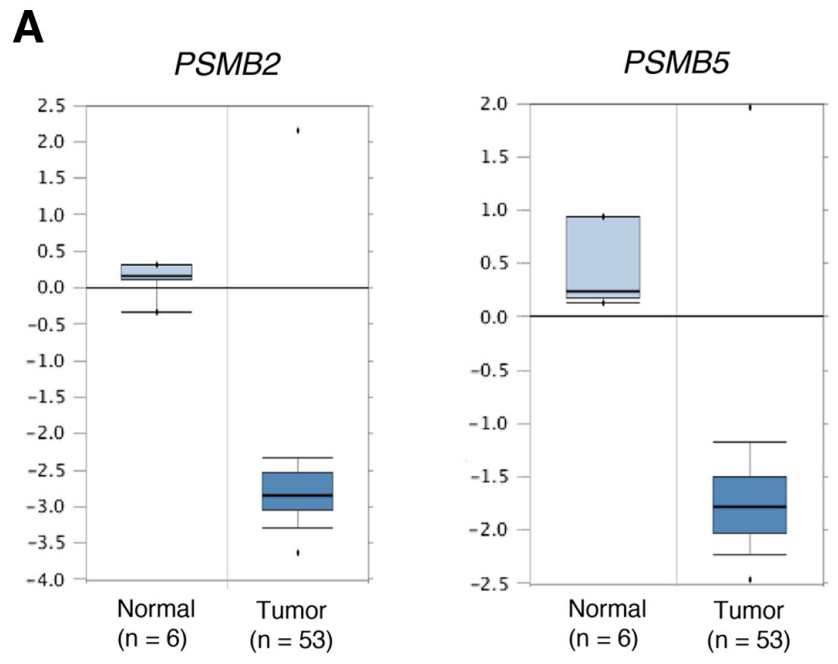

B

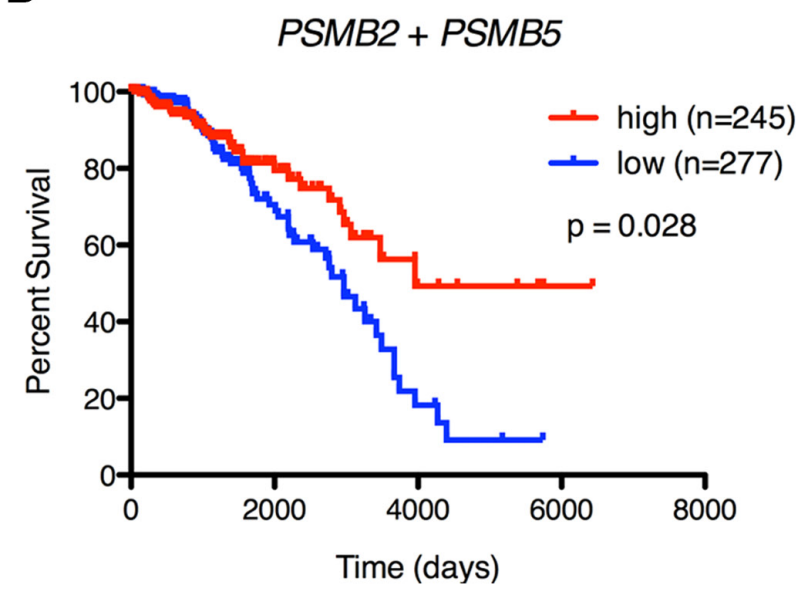

Figure 4: Low proteasome subunit expression is associated with breast tissue from patients with breast cancer and decreased patient survival. A. PSMB2 and PSMB5 gene expression box plots from normal and tumor samples from the Finak dataset [47]. $P<0.01$ for both comparisons. B. Kaplan-Meier survival curves for breast cancer patients stratified by intra-tumor expression ("high" vs "low") of PSMB2 and PSMB5 mRNA. 
Table 1: IPA analysis of differentially expressed genes.

\begin{tabular}{|c|c|c|c|c|}
\hline \multirow[b]{2}{*}{ Category } & \multirow[b]{2}{*}{$\begin{array}{c}\text { No. of } \\
\text { molecules }\end{array}$} & \multicolumn{3}{|c|}{$p$-value } \\
\hline & & HMLE-Snail & HMLE $+\beta 2$ inhib. & HMLE + $\beta 5$ inhib. \\
\hline Cellular Movement & 292 & $6.6 \times 10^{-21}$ & $2.2 \times 10^{-11}$ & $1.4 \times 10^{-11}$ \\
\hline Cell Death \& Survival & 424 & $4.0 \times 10^{-20}$ & $6.4 \times 10^{-16}$ & $4.3 \times 10^{-15}$ \\
\hline Cellular Growth \& Proliferation & 432 & $1.6 \times 10^{-18}$ & $7.5 \times 10^{-15}$ & $5.4 \times 10^{-14}$ \\
\hline Cell Cycle & 233 & $7.9 \times 10^{-16}$ & $1.5 \times 10^{-10}$ & $2.8 \times 10^{-13}$ \\
\hline Epithelial-Mesenchymal Transition & 24 & $4.0 \times 10^{-4}$ & $7.7 \times 10^{-3}$ & $\mathrm{n} / \mathrm{a}$ \\
\hline $\begin{array}{l}\text { Cell Cycle: G2/M DNA Damage } \\
\text { Checkpoint Regulation }\end{array}$ & 23 & $5.4 \times 10^{-9}$ & $1.1 \times 10^{-6}$ & $7.0 \times 10^{-7}$ \\
\hline TGF- $\beta 1$ Signaling & 99 & $1.9 \times 10^{-23}$ & $1.2 \times 10^{-20}$ & $1.0 \times 10^{-22}$ \\
\hline
\end{tabular}

Transcripts differentially expressed in $\beta 2$ or $\beta 5$ inhibitor-treated HMLE cells are enriched in molecular and cellular functions involved in EMT.

\section{Selective inhibition of proteasome activity induces an EMT transcriptional program}

To investigate the molecular mechanisms underlying proteasome inhibitor-induced EMT, we performed gene expression microarray analysis of DMSO-treated HMLE cells, cells treated with either $\beta 2$ or $\beta 5$ subunit inhibitors, and cells expressing Snail. 1,338 and 1,278 genes were differentially expressed in $\beta 2$ and $\beta 5$ subunit inhibitortreated HMLE cells, respectively, compared to DMSOtreated cells. Among these differentially expressed genes were a number of transcripts that have been previously reported to be associated with EMT (Figure 5A). These included a number of upregulated mesenchymal markers $I D 1, K L K 7, L C N 2$, and CEACAM6 as well as downregulated epithelial markers FOXA2, MIR205, and $C O L 4 A 2$ [9]. Moreover, key genes were validated by qPCR and we found that $\beta 2$ and $\beta 5$ inhibitor-treated HMLE cells exhibited increased expression of the EMTassociated transcription factors, SNAI1, ZEB1/2, and TWIST1, as well as decreased expression of epithelial markers $C D H 1$, TJP1, and CLDN1 (Figure 5B).

Gene set enrichment analysis (GSEA) revealed that transcripts upregulated or downregulated upon proteasome inhibitor treatment were significantly enriched within the set of genes upregulated or downregulated in HMLESnail, respectively (Figure 5C). These observations were confirmed by additional GSEA using datasets derived from the Molecular Signatures Database (Supplementary Table 1). Lastly, we applied Ingenuity Pathway Analysis (IPA) to the transcripts that were differentially expressed between $\beta 2$ or $\beta 5$ subunit inhibitor-treated HMLE cells and DMSO-treated cells. This analysis identified cellular movement, cell death and survival, cell growth and proliferation, and EMT as some of the most significantly enriched molecular and cellular functions across all samples (Table 1 and Figure 5D). Taken together, these analyses provide molecular evidence that $\beta 2$ or $\beta 5$ subunit inhibition induces HMLE cells to undergo EMT.

\section{Selective proteasome inhibitor induces an EMT transcriptional program by stabilizing the TGF- $\beta 1$ signaling pathway}

In addition to identifying a link between proteasome inhibition and the EMT pathway, IPA analysis also identified the TGF- $\beta 1$ signaling pathway as a putative upstream regulator driving the observed transcriptional changes in proteasome-inhibited HMLE cells (Table 1 and Figure $6 \mathrm{~A}$ ). TGF- $\beta 1$ signals through tetrameric TGF- $\beta$ receptors 1 (TGFR1) and 2 (TGFR2) complexes, which phosphorylate SMAD2 (pSMAD2). SMAD4 combines with pSMAD2 to form multimeric SMAD-complexes that translocate into the nucleus and regulate transcription [9]. We hypothesized that reduced proteasome activity might result in increased stability of TGFR2 leading to increased TGF- $\beta 1$ signaling. In support of this hypothesis, we observed increased cell surface expression of TGFR2 in HMLE cells treated with $\beta 2$ subunit inhibitor (Figure $6 \mathrm{~B})$. Moreover, we found that treatment with $\beta 2$ subunit inhibitor increased SMAD2 phosphorylation (Figure 6C) and increased SMAD4 nuclear localization by 2-fold 
A

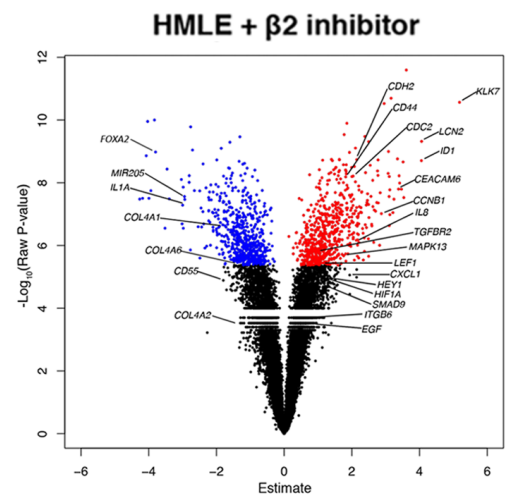

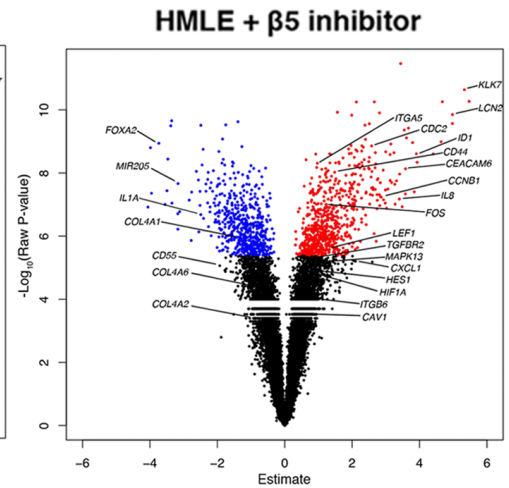

C

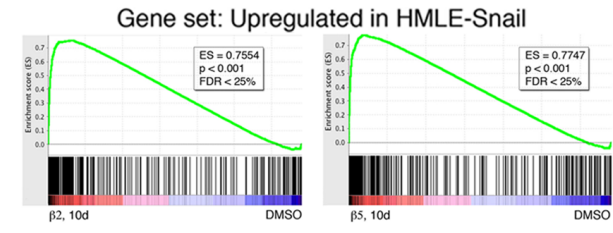

Gene set: Downrequlated in HMLE-Snail

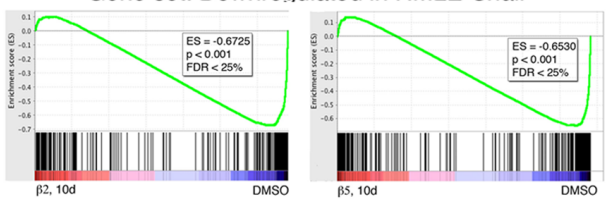

B

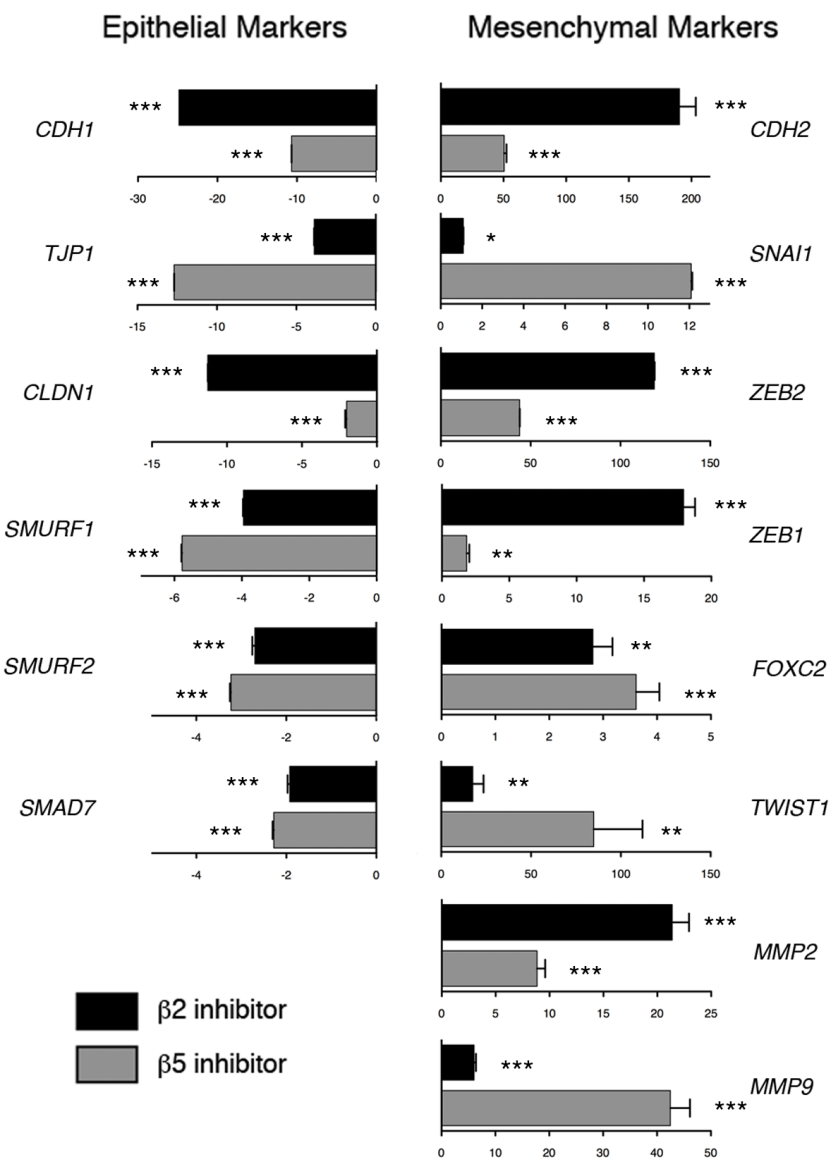

D
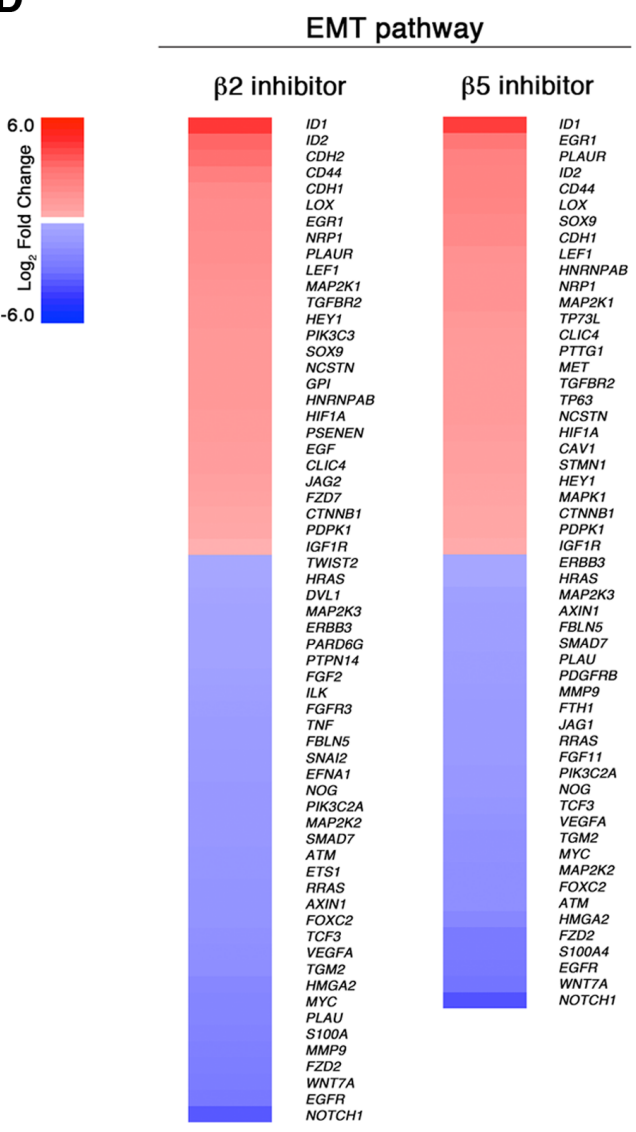

Fold Change Relative to DMSO

Figure 5: Selective inhibition of proteasome activity induces an EMT transcriptional program. A. Volcano plots depicting differentially expressed genes in HMLE cells treated with $\beta 2$ or $\beta 5$ subunit inhibitors compared to DMSO-treated cells after 10 days. $\mathrm{X}$-axis represents the Array Studio estimate and the $\mathrm{y}$-axis represents the $-\log _{10}(\mathrm{Raw} P$-value). Significant differentially expressed genes are highlighted in red (upregulated) or in blue (downregulated). Selected genes of interest are indicated. B. mRNA levels of epithelial and mesenchymal markers in sorted CD44 high HMLE cells treated with $\beta 2$ (black bars) or $\beta 5$ inhibitor (grey bars). GAPDH was used as a reference gene. Data are shown as fold change relative to DMSO-treated HMLE. Error bars indicate SEM $(n \geq 3)$. C. GSEA plots. Enrichment score is visualized in green. ES, enrichment score. FDR, false discovery rate. D. Heatmaps depicting $\log _{2}$ fold change of differentially expressed genes in the EMT pathway in HMLE cells treated with $\beta 2$ or $\beta 5$ subunit inhibitors compared to DMSO-treated cells. Gene list was generated with IPA. 
(Figure 6D), compared to DMSO-treated cells. In line with these results, we also observed increased mRNA expression of SMAD target genes $S N A I 1, Z E B 1 / 2, M M P 2$, and $M M P 9$, as well as decreased expression of $S M A D 7$, a negative regulator of TGF- $\beta 1$ signaling (Figure 5B).

To confirm that EMT induction in proteasome inhibitor-treated HMLE cells is due to TGF- $\beta 1$ signaling, we repeated inhibitor treatment in the presence of an anti-TGF- $\beta 1$ neutralizing antibody. We first validated the specificity of the neutralizing antibody in our system by showing that SMAD2 phosphorylation is blocked when
HMLE cells are treated with TGF- $\beta 1$ or proteasome inhibitors in the presence of the neutralizing antibody (Supplementary Figure S5A-B). Strikingly, we found that neutralizing anti-TGF- $\beta 1$ antibodies prevented the $\beta 2$ subunit inhibitor-induced increase in CD44 cell surface expression (Figure 7A). Moreover, EMT-associated downregulation of E-cadherin and upregulation of fibronectin and vimentin, both at the protein and mRNA level, were prevented by anti-TGF- $\beta 1$ antibody treatment (Figure 7B-7D). Taken together, these data suggest that a consequence of decreased $\beta 2$ subunit proteasome activity

A TGF $\beta 1$ signaling pathway

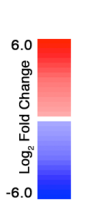

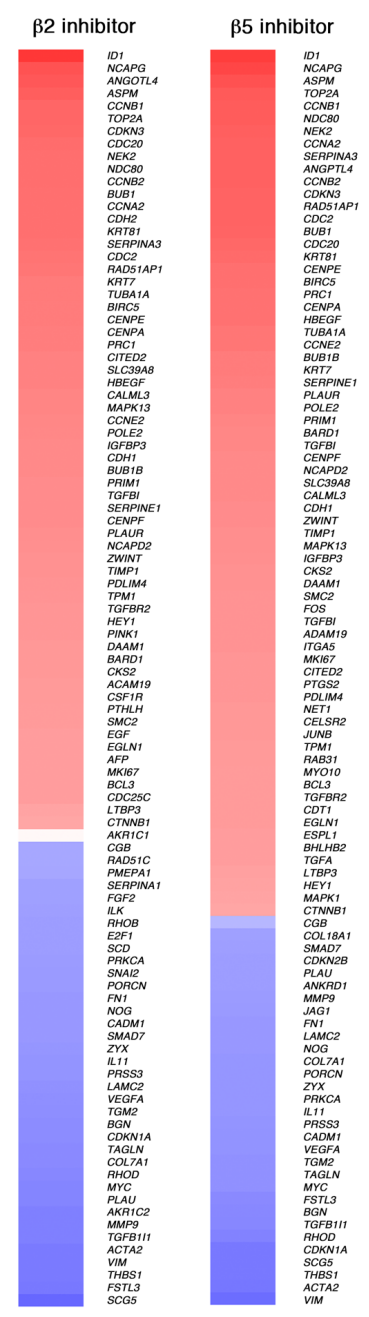

D
B

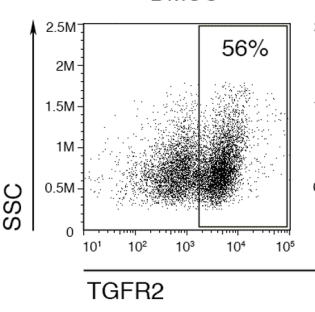

$\beta 2$ inhibitor

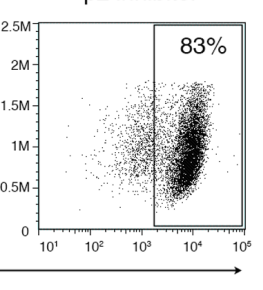

DAPI

$$
\text { Smad4 }
$$

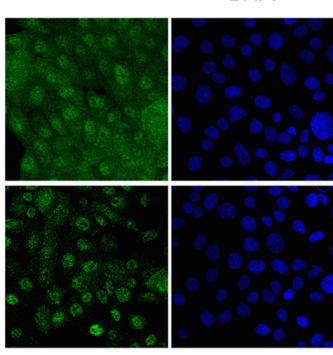

Merged

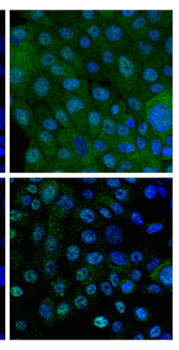

C

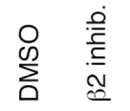

anti-Phospho-Smad2/3

(Ser465/467)

anti-Actin
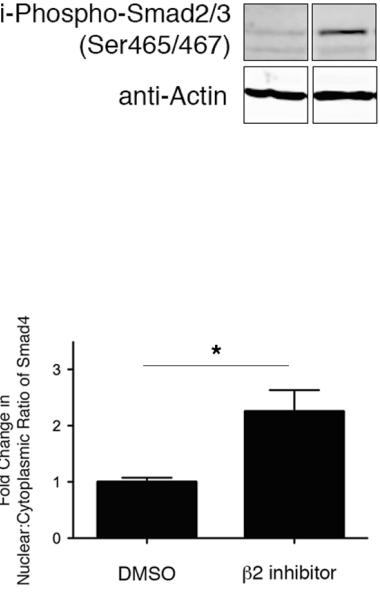

Figure 6: Downregulation of proteasome activity enhances TGF- $\beta 1$ signaling. A. Heatmaps depicting Log fold change of differentially expressed genes in the TGF- $\beta 1$ signaling pathway in HMLE cells treated with $\beta 2$ or $\beta 5$ subunit inhibitors compared to DMSO-treated cells. B. Flow cytometric analysis of surface TGFR2 expression and SSC by HMLE cells treated for 1 day with DMSO or $\beta 2$ subunit inhibitor. Percentage of TGFR2 ${ }^{+}$cells within the live population is indicated. Representative result of three independent experiments is shown. C. Immunoblot using anti-Phospho Smad2 (Ser465/467) antibody on whole cell lysates from DMSO- or beta2 inhibitor-treated HMLE cells for 24 hours representative of 3 independent experiments. $\beta$-actin served as a loading control. Vertical spaces inserted between lanes indicate removal of intervening, irrelevant samples. All the samples were ran on the same gel, transferred and blotted together, and imaged in a single scan. D. Confocal microscopy of Smad4 (green) and DNA (blue; stained with DAPI) in HMLE cells treated with $\beta 2$ subunit inhibitor for 3 hours. Images were taken at 40X magnification. Bar graph presents fold change in nuclear/cytoplasmic ratio relative to control treatment. Error bars indicate SEM $(n \geq 3)$. 
A

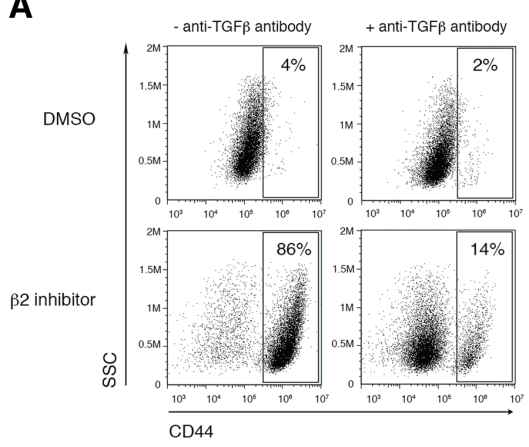

B
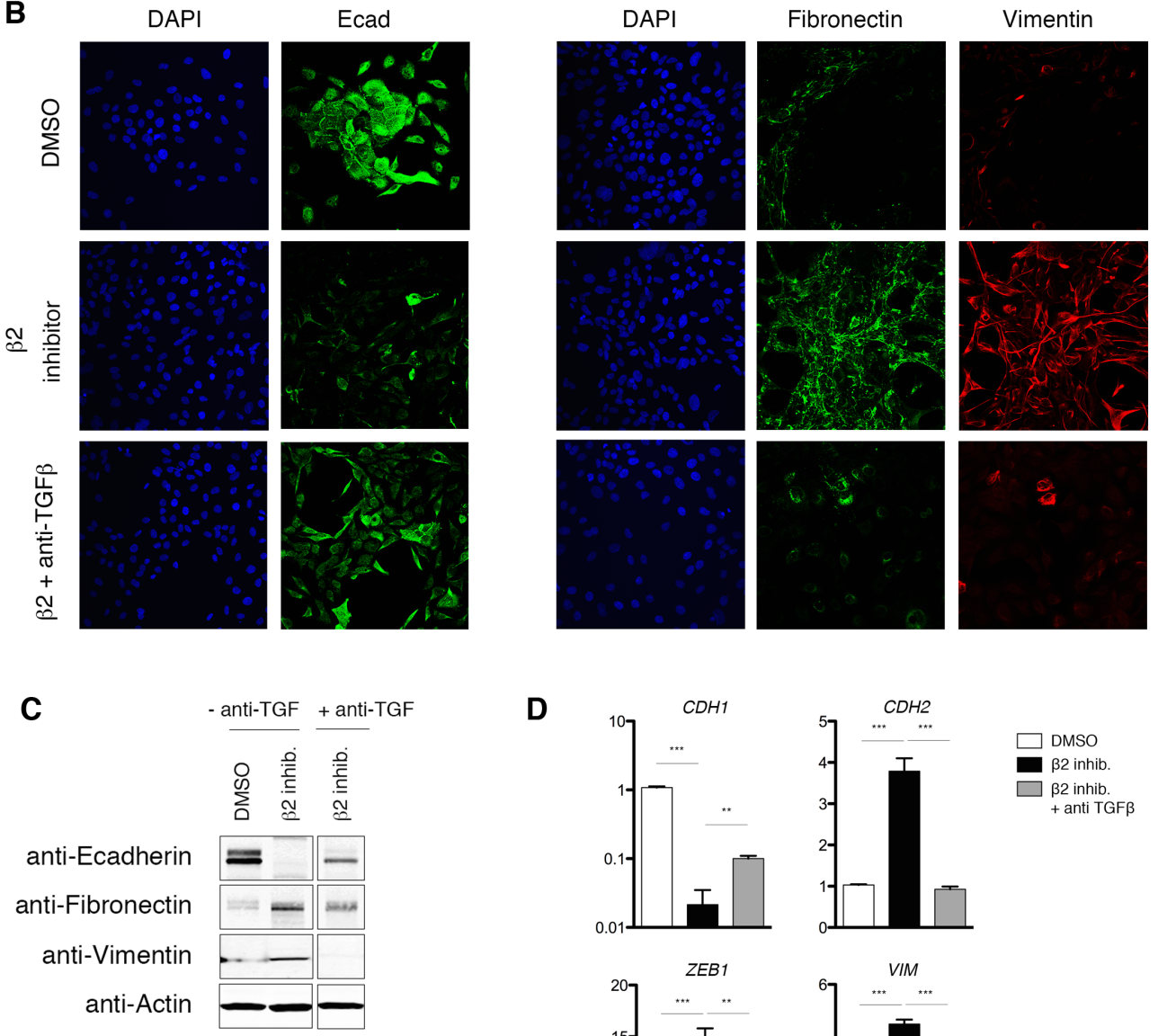

D
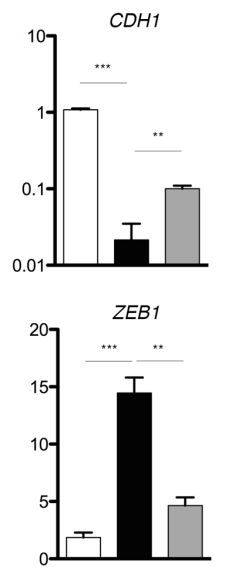
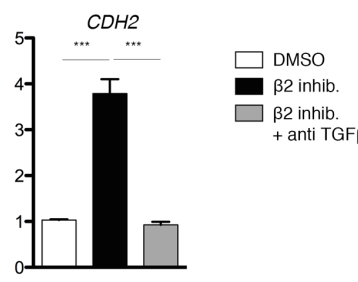

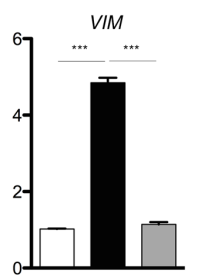

Figure 7: Proteasome inhibitor-induced EMT is dependent on TGF- $\beta 1$ signaling. A. Flow cytometric analysis of CD44 expression after 14 days of treatment with DMSO or $\beta 2$ inhibitor, with or without neutralizing anti-TGF- $\beta 1$ antibody. Percentage of CD44 high cells within the live population is indicated. Representative result of three independent experiments is shown. B. Confocal microscopy of E-cadherin (left panel; green), fibronectin (right panel; green), or vimentin (red) in HMLE cells, HMLE cells+ $\beta 2$ subunit inhibitor, or HMLE cells $+\beta 2$ subunit inhibitor with anti-TGF- $\beta 1$ antibody for 14 days. Images were taken at $40 \mathrm{X}$ magnification. C. Immunoblot of whole cell lysates from HMLE, HMLE $+\beta 2$ inhibitor, or HMLE cells $+\beta 2$ subunit inhibitor treated with anti-TGF- $\beta 1$ antibody, using antiE-cadherin, anti-fibronectin, and anti-vimentin antibodies. Images are representative of 3 independent experiments. $\beta$-Actin served as a loading control. Vertical spaces inserted between lanes indicate removal of intervening, irrelevant samples. All the samples were ran on the same gel, transferred and blotted together, and imaged in a single scan. D. mRNA levels of epithelial (CDH1) and mesenchymal markers $(C D H 2, Z E B 1$, and VIM) in HMLE or HMLE+ $\beta 2$ inhibitor treated with or without neutralizing anti-TGF- $\beta 1$ antibody. GAPDH was used as a reference gene. Data are shown as fold change relative to DMSO-treated HMLE. Error bars indicate SEM $(n \geq 3)$. 
in HMLE cells is the stabilization of the TGFR2 at the cell surface, thereby resulting in increased TGF- $\beta 1$ signaling and induction of the EMT transcriptional program.

\section{DISCUSSION}

It is established that EMT can generate cells with CSC properties, but the molecular mechanisms that induce EMT have not been fully elucidated. In the present study, we found that epithelial cells decrease their proteasome activity during EMT and that proteasome inhibitors can induce EMT. Mechanistically, we show that one consequence of downregulated proteasome activity may be increased TGF- $\beta 1$ signaling, a potent inducer of EMT. However, it remains possible that a decrease in proteasome activity may enhance the stability of other EMT-promoting factors. For example, glycogen synthase kinase-3 $\beta$ (GSK3 $\beta$ )-mediated phosphorylation of SNAI1 has been shown to facilitate its nuclear export and degradation [9, 33], while SNAI2 can undergo proteasome-dependent degradation mediated by the p53-MDM2 complex [9, 34]. In addition, phosphorylation of TWIST1 by the MAPK p38-JNK-ERK complex protects it from degradation [9, 35]. Thus, downregulation of proteasome activity may lead to the induction of the EMT program through effects mediated by other pathways in addition to enhanced TGF- $\beta 1$ signaling.

In support of the potential clinical relevance of our observations, we show that proteasome subunit mRNA expression in human tumor samples correlates with disease progression (Figure 4A, 4B). These results are consistent with the finding that low expression of $19 \mathrm{~S}$ proteasome subunit PSMD1 correlates with decreased probability of overall survival in a cohort of 82 head and neck squamous cell carcinoma patients [11]. Conversely, high expression of proteasome subunits PSMB7 [36] and PSMB4 [37] has been shown to be associated with decreased breast cancer patient survival and poor prognosis, respectively. The extent to which the expression of PSMD1, PSMB4, and $P S M B 7$ affect proteasome activity remains poorly understood, and may provide a possible explanation for these contrasting observations. To our knowledge, ours is the first study that suggests a correlation between decreased expression of the catalytic proteasome subunits - PSMB2 and PSMB5 - and reduced survival of breast cancer patients.

Finally, our findings are intriguing in light of the clinical use of proteasome inhibitors for the treatment of cancer. While many patients with hematopoietic malignancies respond to the proteasome inhibitor bortezomib, clinical trials investigating the use of proteasome inhibitors for solid tumors have thus far been disappointing [38-40]. Our data suggest a possible molecular mechanism for this observed effect - that pharmacologic inhibition of the proteasome may result in induction of EMT and acquisition of certain attributes of CSCs. Paradoxically, our results also suggest the possibility that pharmacologic inhibition of the proteasome may not only induce EMT in breast cancer cells, but may also endow them with an enhanced capacity to survive against the stimuli that led to their induction in the first place (Figure 2E). Taken together, these results suggest caution in the use of proteasome inhibitors in tumor subtypes that follow the CSC paradigm and raise the possibility that the use of agents that activate the proteasome, such as inhibitors of the deubiquitinase USP14 [41], might instead be an effective therapeutic strategy in such cancers.

\section{MATERIALS AND METHODS}

\section{Mice}

All animal work was approved by the Institutional Animal Care and Use Guidelines of the University of California, San Diego. All mice were housed in specific pathogen-free conditions prior to use.

\section{Cell culture}

Immortalized human mammary epithelial cells (HMLE), HMLE-Snail, HMLE-Twist, HMLE-Ras (HMLER), and HMLER-Twist were maintained as previously described [32, 42]. MCF10A cells were obtained from Dr. Karra Muller (UCSD) and cultured in Dulbecco's Modified Eagle's Medium/Nutrient Mixture F-12 supplemented with 5\% FBS, 20ng/ml EGF, 0.5mg/ $\mathrm{ml}$ Hydrocortisone, 10ug/ml Insulin, 100ng/ml Cholera toxin, and Penicillin-Streptomycin. TGF- $\beta 1$ treatment was performed as previously reported [6]. Epoxomicin (Enzo Life Sciences) was used at $12.5 \mu \mathrm{M}$. Anti-TGF- $\beta 1$ neutralizing antibodies (Bio X Cell) were used at a concentration of $10 \mu \mathrm{g} / \mathrm{mL}$.

\section{Activity-based proteasome probes and proteasome inhibitors}

Subunit-selective activity-based proteasome probes, MVB003 (pan-reactive), LW124 ( $\beta 1$ subunit-reactive), and PR592 ( $\beta 5$ subunit-reactive) and subunit-selective proteasome inhibitors, NC001 ( $\beta 1$ subunit-reactive), LU102 ( $\beta 2$ subunit-reactive), and LU005 ( $\beta 5$ subunitreactive) were reconstituted in DMSO and have been previously described (Supplementary Figure S1) [2427]. In brief, the proteasome inhibitors were designed for selective and irreversible binding to proteolytically active proteasome subunits. Activity-based probes (ABPs) are similar to the proteasome inhibitors, except that they carry a fluorescent group that allows visualization of proteins 
bands by SDS-PAGE. For selective proteasome inhibition, cells were cultured in media containing $5 \%$ fetal bovine serum in the presence of $5 \mu \mathrm{M} \beta 1$ inhibitor, $5 \mu \mathrm{M} \beta 2$ inhibitor, or $0.5 \mu \mathrm{M} \beta 5$ inhibitor up to 14 days. For analysis of short-term effects of proteasome inhibition on TGF- $\beta$ signaling, cells were treated for 24 hours.

\section{In-gel proteasome activity assay}

Cells were mechanically disrupted in 50mM Tris, $\mathrm{pH} 7.4 .100 \mu \mathrm{g}$ of total protein was incubated with $0.5 \mu \mathrm{M}$ pan-reactive probe (MVB003), $0.5 \mu \mathrm{M} \beta 1$ probe (LW124), or $1 \mu \mathrm{M} \beta 5$ probe (PR592) for $3 \mathrm{hrs}$ at $37^{\circ} \mathrm{C}$ in $50 \mathrm{mM}$ Tris, pH7.4 buffer supplemented with $5 \mathrm{mM} \mathrm{MgCl}_{2}, 250 \mathrm{mM}$ sucrose, $1 \mathrm{mM}$ DTT, and $2 \mathrm{mM}$ ATP. After the reaction, samples were resolved on Novex 4-20\% Tris-Glycine Mini Protein Gels (Life Technologies) and the fluorescent signals were detected using FluorChem Q (ProteinSimple). Densitometry was used to quantify the signals. Because the activity-based probes bind stoichiometrically to selective proteasome subunits, the fluorescent signal measured is linearly proportional to the activity of the specific $\beta$ subunit. Beta 2 subunit activity was determined by using the pan-reactive probe (MVB003) and analyzing the the fluorescent band at $\sim 23 \mathrm{kDa}$.

\section{Immunoblotting and antibodies}

Cells were lysed on ice in buffer containing $50 \mathrm{mM}$ HEPES, pH7.4, 80mM NaCl, $5 \mathrm{mM} \mathrm{MgCl} 2,10 \mathrm{mM}$ EDTA, $5 \mathrm{mM}$ sodium pyrophosphate $* 10 \mathrm{H}_{2} \mathrm{O}, 1 \%$ TritonX-100, and Protease Inhibitor Cocktail (Sigma-Aldrich). $30 \mu \mathrm{g}$ of total protein from each sample was resolved on Novex 4-20\% Tris-Glycine Mini Protein Gels and transferred onto nitrocellulose membranes. The blots were probed with the appropriate antibodies: anti-ubiquitin (Cell Signaling Technology), anti- $\beta$-actin (Sigma-Aldrich), anti20S/ $\beta 1$ subunit (Santa Cruz Biotechnology, Inc.), anti-20S/ $\beta 2$ subunit (Santa Cruz Biotechnology, Inc.), anti-20S/ $\beta 5$ subunit (Santa Cruz Biotechnology, Inc.), anti-E-cadherin (BD Biosciences), anti-fibronectin (BD Biosciences), anti-vimentin (Cell Signaling Technology), anti-phosphoSmad2 (Ser465/467) (Cell Signaling Technology), or anti-Smad2/3 (Cell Signaling Technology). Signals were detected using Odyssey infrared imaging system (LI-Cor Biosciences).

\section{Flow cytometry analysis and cell sorting}

Suspensions of HMLE or MCF10A cells were stained with anti-CD44 antibody (Biolegend), anti-CD24 antibody (Biolegend), 7-AAD (eBioscience), Annexin-V (eBioscience), or anti-TGFR2 antibody (R\&D Systems) and analyzed by flow cytometry on a BD Accuri C6
(BD Biosciences). Data were analyzed using FlowJo software. Cell sorting was done using at FACSAria (BD Biosciences) at the UCSD Human Embryonic Stem Cell Core Facility.

\section{Mammosphere culture}

Mammosphere culture was performed as previously described [6, 43], except that 2000 single cells for the primary culture and 1000 dissociated cells for the serial passages were plated per well of a 24 -well plate. For serial passage studies, mammospheres were first dissociated into single cells and then plated in mammosphere culture conditions. This process was repeated three times.

\section{Tumorigenesis assay}

Five million HMLER cells per group (control HMLER, HMLER-Twist, or HMLER $+\beta 2$ inhibitor) were injected subcutaneously into homozygous nude mice. A total of 12 animals were used for each condition. The tumor incidence and the tumor size were monitored for two months following injection.

\section{Confocal microscopy}

Following growth on coverslips for 2 days and treatment with DMSO, $\beta 2$ inhibitor, $\beta 5$ inhibitor or TGF- $\beta 1$ with or without anti-TGF- $\beta 1$ antibodies, immunofluorescence of HMLEs and MCF10A was performed as previously described [44] using antiE-cadherin (BD Biosciences), anti-fibronectin (BD Biosciences), anti-vimentin (Cell Signaling Technology), or anti-Smad4 (B-8) (Santa Cruz Biotechnology) followed by anti-rabbit Alexa Fluor 555 or anti-mouse Alexa Fluor 488 (Life Technologies) antibodies. DAPI (Life Technologies) was used to detect DNA. Acquisition of image stacks was performed as previously described [44] using a FV1000 laser scanning confocal microscope (Olympus). Fluorescence within the nucleus or cytoplasm was quantified using ImageJ software.

\section{Microarray analysis}

Total RNA was isolated from HMLE cells using TRIzol (Life Technologies). RNA was extracted from TRIzol using chloroform and precipitated with isopropanol. cDNA was then synthesized using the High Capacity cDNA Reverse Transcription Kit (Life Technologies) and hybridized to HumanHT-12_v4 arrays according to standard protocols (Illumina). Raw data were quantile normalized.

Differential expression analysis of Affymetrix array data was conducted using the Array Studio analysis suite 
(Omicsoft, Inc). Datasets were quantile-normalized at the gene-level and log-transformed before computing oneway ANOVA statistics between treatment and control group samples. Principal component analysis was used to detect possible outliers and batch effects across samples. Differentially expressed gene signatures representing $1-5 \%$ of the coding transcriptomes were generated using a FDR $<0.0001$. Functional enrichment of the differentially expressed genes was performed using GSEA, as previously described $[45,46]$, and IPA (Ingenuity). Genes significantly upregulated and downregulated in HMLESnail were used as the enrichment set. Other enrichment sets used were taken from the Molecular Signatures Database [45]. Enrichment set names are included in Supplementary Table 1.

\section{Real-time quantitative PCR}

Total RNA was extracted using TRIzol (Life Technologies) and was reverse-transcribed with MultiScribe Reverse Transcriptase (Life Technologies). The resulting cDNAs were used for qPCR using SsoAdvance SYBR Green Supermix (Bio-Rad) in triplicate. PCR and data collection were performed on CFX96 Touch Real-Time PCR Detection System (BioRad). All the values were normalized to an internal control GAPDH. Relative expression for each target gene was compared to that of HMLE or MCF10A, and the data were presented as relative fold change. See Supplementary Information for primer sequences.

\section{Kaplan-Meier analysis}

Kaplan-Meier survival curves were generated from The Cancer Genome Atlas Breast Invasive Carcinoma Illumina HiSeq gene expression dataset $(n=1215)$. Patients were stratified based on the combined expression of proteasome catalytic subunit genes PSMB2 and $P S M B 5$. High and low expression is defined as the top $20 \%(n=245$ of 1215$)$ and bottom $22 \%(n=277$ of 1215$)$ of the patient distribution, respectively. Expression and overall survival data were downloaded from the UCSC Cancer Genomics Browser (https://genome-cancer.ucsc. edu/). Prism (GraphPad) was used to test the statistical significance between the overall survival curves using the Log-rank (Mantel-Cox) Test.

\section{Oncomine analysis}

Oncomine Platform (v4.5, Life Technologies) was used to analyze single gene expression in normal versus tumor samples, using the Finak Breast dataset [47].

\section{Statistics}

Statistical analyses were performed with a unpaired $t$ test using GraphPad Software. The resulting statistics are indicated in each figure as follows: $\mathrm{ns}=$ Not significant $(P$ $>0.05)$, Significant: $*=(P \leq 0.05), * *=(P \leq 0.01), * * *=$ $(P \leq 0.001), * * * *=(P \leq 0.0001)$.

\section{ACKNOWLEDGMENTS}

Microarray analysis was conducted at the IGM Genomics Center, University of California, San Diego, La Jolla, CA with support from NIH-NCI-P30CA023100. J.T.C. is a Howard Hughes Medical Institute PhysicianScientist Early Career Awardee and a V Foundation for Cancer Research V Scholar Awardee. D.A.G. is a Howard Hughes Medical Institute Gilliam Fellow. E.D.V.B. is supported by CIRM-Bridges Grant number TB1-01186. We thank the members of the Chang and Bui laboratory for helpful discussions.

\section{CONFLICTS OF INTEREST}

No potential conflicts of interest were disclosed.

\section{GRANT SUPPORT}

This work was supported by NIH grants DK093507, OD008469, AI095277 (J.T.C.), and CA157885 (J.D.B.), CA168689 and CA174869 (J.Y.), the Hartwell Foundation (J.D.B.), the UCSD Digestive Diseases Research Development Center Grant DK80506, and the UCSD Neuroscience Microscopy Shared Facility Grant P30 NS047101.

\section{Authors' contributions}

Conception and design: A. Banno, D. Garcia, J. Bui, J. Yang, J. Chang

Development of methodology: A. Banno, D. Garcia, P. Geurink, B. Florea, H. Overkleeft, H. Ovaa, J. Bui, J. Yang

Acquisition of data: A. Banno, D. Garcia, E. van Baarsel, P. Metz, C. Widjaja, S. Kim, J. Lopez

Analysis and interpretation of data: A. Banno, D. Garcia, K. Fisch, A. Chang

Writing, review, and/or revision of the manuscript: A. Banno, D. Garcia, J. Chang

\section{REFERENCES}

1. Yang CH, Gonzalez-Angulo AM, Reuben JM, Booser DJ, Pusztai L, Krishnamurthy S, Esseltine D, Stec J, Broglio KR, Islam R, Hortobagyi GN and Cristofanilli 
M. Bortezomib (VELCADE) in metastatic breast cancer: pharmacodynamics, biological effects, and prediction of clinical benefits. Ann Oncol. 2006; 17:813-817.

2. Chaffer CL and Weinberg RA. A perspective on cancer cell metastasis. Science. 2011; 331:1559-1564.

3. Pattabiraman DR and Weinberg RA. Tackling the cancer stem cells - what challenges do they pose? Nat Rev Drug Discov. 2014; 13:497-512.

4. Chang JT and Mani SA. Sheep, wolf, or werewolf: cancer stem cells and the epithelial-to-mesenchymal transition. Cancer Lett. 2013; 341:16-23.

5. Hennessy BT, Gonzalez-Angulo AM, Stemke-Hale K, Gilcrease MZ, Krishnamurthy S, Lee JS, Fridlyand J, Sahin A, Agarwal R, Joy C, Liu W, Stivers D, Baggerly K, Carey M, Lluch A, Monteagudo C, et al. Characterization of a naturally occurring breast cancer subset enriched in epithelial-to-mesenchymal transition and stem cell characteristics. Cancer Res. 2009; 69:4116-4124.

6. Mani SA, Guo W, Liao MJ, Eaton EN, Ayyanan A, Zhou AY, Brooks M, Reinhard F, Zhang CC, Shipitsin M, Campbell LL, Polyak K, Brisken C, Yang J and Weinberg RA. The epithelial-mesenchymal transition generates cells with properties of stem cells. Cell. 2008; 133:704-715.

7. Morel AP, Lievre M, Thomas C, Hinkal G, Ansieau S and Puisieux A. Generation of breast cancer stem cells through epithelial-mesenchymal transition. PLoS One. 2008; 3:e2888.

8. Ouyang G, Wang Z, Fang X, Liu J and Yang CJ. Molecular signaling of the epithelial to mesenchymal transition in generating and maintaining cancer stem cells. Cell Mol Life Sci. 2010; 67:2605-2618.

9. Lamouille S, Xu J and Derynck R. Molecular mechanisms of epithelial-mesenchymal transition. Nat Rev Mol Cell Biol. 2014; 15:178-196.

10. De Craene B and Berx G. Regulatory networks defining EMT during cancer initiation and progression. Nat Rev Cancer. 2013; 13:97-110.

11. Lagadec C, Vlashi E, Bhuta S, Lai C, Mischel P, Werner M, Henke $\mathrm{M}$ and Pajonk F. Tumor cells with low proteasome subunit expression predict overall survival in head and neck cancer patients. BMC Cancer. 2014; 14:152.

12. Lagadec C, Vlashi E, Della Donna L, Meng Y, Dekmezian C, Kim K and Pajonk F. Survival and self-renewing capacity of breast cancer initiating cells during fractionated radiation treatment. Breast Cancer Res. 2010; 12:R13.

13. Pan J, Zhang Q, Wang Y and You M. 26S proteasome activity is down-regulated in lung cancer stem-like cells propagated in vitro. PLoS One. 2010; 5:e13298.

14. Vlashi E, Kim K, Lagadec C, Donna LD, McDonald JT, Eghbali M, Sayre JW, Stefani E, McBride W and Pajonk F. In vivo imaging, tracking, and targeting of cancer stem cells. J Natl Cancer Inst. 2009; 101:350-359.

15. Vlashi E, Lagadec C, Chan M, Frohnen P, McDonald AJ and Pajonk F. Targeted elimination of breast cancer cells with low proteasome activity is sufficient for tumor regression. Breast Cancer Res Treat. 2013; 141:197-203.

16. Adams J. The proteasome: structure, function, and role in the cell. Cancer Treat Rev. 2003; 29 Suppl 1:3-9.

17. Crawford LJ, Walker B and Irvine AE. Proteasome inhibitors in cancer therapy. J Cell Commun Signal. 2011; 5:101-110.

18. Yang J, Mani SA, Donaher JL, Ramaswamy S, Itzykson RA, Come C, Savagner P, Gitelman I, Richardson A and Weinberg RA. Twist, a master regulator of morphogenesis, plays an essential role in tumor metastasis. Cell. 2004; 117:927-939.

19. Yang J, Mani SA and Weinberg RA. Exploring a new twist on tumor metastasis. Cancer Res. 2006; 66:4549-4552.

20. Batlle E, Sancho E, Franci C, Dominguez D, Monfar M, Baulida $\mathrm{J}$ and Garcia De Herreros A. The transcription factor snail is a repressor of E-cadherin gene expression in epithelial tumour cells. Nat Cell Biol. 2000; 2:84-89.

21. Cano A, Perez-Moreno MA, Rodrigo I, Locascio A, Blanco MJ, del Barrio MG, Portillo F and Nieto MA. The transcription factor snail controls epithelial-mesenchymal transitions by repressing E-cadherin expression. Nat Cell Biol. 2000; 2:76-83.

22. Miettinen PJ, Ebner R, Lopez AR and Derynck R. TGF-beta induced transdifferentiation of mammary epithelial cells to mesenchymal cells: involvement of type I receptors. J Cell Biol. 1994; 127:2021-2036.

23. Berkers CR, van Leeuwen FW, Groothuis TA, Peperzak V, van Tilburg EW, Borst J, Neefjes JJ and Ovaa H. Profiling proteasome activity in tissue with fluorescent probes. Mol Pharm. 2007; 4:739-748.

24. Li N, Kuo CL, Paniagua G, van den Elst H, Verdoes M, Willems LI, van der Linden WA, Ruben M, van Genderen E, Gubbens J, van Wezel GP, Overkleeft HS and Florea BI. Relative quantification of proteasome activity by activitybased protein profiling and LC-MS/MS. Nat Protoc. 2013; 8:1155-1168.

25. Geurink PP, Liu N, Spaans MP, Downey SL, van den Nieuwendijk AM, van der Marel GA, Kisselev AF, Florea BI and Overkleeft HS. Incorporation of fluorinated phenylalanine generates highly specific inhibitor of proteasome's chymotrypsin-like sites. J Med Chem. 2010; 53:2319-2323.

26. Britton M, Lucas MM, Downey SL, Screen M, Pletnev AA, Verdoes M, Tokhunts RA, Amir O, Goddard AL, Pelphrey PM, Wright DL, Overkleeft HS and Kisselev AF. Selective inhibitor of proteasome's caspase-like sites sensitizes cells to specific inhibition of chymotrypsin-like sites. Chem Biol. 2009; 16:1278-1289.

27. Geurink PP, van der Linden WA, Mirabella AC, Gallastegui $\mathrm{N}$, de Bruin G, Blom AE, Voges MJ, Mock ED, Florea BI, van der Marel GA, Driessen C, van der Stelt M, Groll M, Overkleeft HS and Kisselev AF. Incorporation of nonnatural amino acids improves cell permeability and potency 
of specific inhibitors of proteasome trypsin-like sites. J Med Chem. 2013; 56:1262-1275.

28. Al-Hajj M, Wicha MS, Benito-Hernandez A, Morrison SJ and Clarke MF. Prospective identification of tumorigenic breast cancer cells. Proc Natl Acad Sci U S A. 2003; 100:3983-3988.

29. Zoller M. CD44: can a cancer-initiating cell profit from an abundantly expressed molecule? Nat Rev Cancer. 2011; 11:254-267.

30. Liao MJ, Zhang CC, Zhou B, Zimonjic DB, Mani SA, Kaba M, Gifford A, Reinhardt F, Popescu NC, Guo W, Eaton EN, Lodish HF and Weinberg RA. Enrichment of a population of mammary gland cells that form mammospheres and have in vivo repopulating activity. Cancer Res. 2007; 67:81318138.

31. Moraes RC, Zhang X, Harrington N, Fung JY, Wu MF, Hilsenbeck SG, Allred DC and Lewis MT. Constitutive activation of smoothened (SMO) in mammary glands of transgenic mice leads to increased proliferation, altered differentiation and ductal dysplasia. Development. 2007; 134:1231-1242.

32. Elenbaas B, Spirio L, Koerner F, Fleming MD, Zimonjic DB, Donaher JL, Popescu NC, Hahn WC and Weinberg RA. Human breast cancer cells generated by oncogenic transformation of primary mammary epithelial cells. Genes Dev. 2001; 15:50-65.

33. Zhou BP, Deng J, Xia W, Xu J, Li YM, Gunduz M and Hung MC. Dual regulation of Snail by GSK-3beta-mediated phosphorylation in control of epithelial-mesenchymal transition. Nat Cell Biol. 2004; 6:931-940.

34. Wang SP, Wang WL, Chang YL, Wu CT, Chao YC, Kao SH, Yuan A, Lin CW, Yang SC, Chan WK, Li KC, Hong TM and Yang PC. p53 controls cancer cell invasion by inducing the MDM2-mediated degradation of Slug. Nat Cell Biol. 2009; 11:694-704.

35. Hong J, Zhou J, Fu J, He T, Qin J, Wang L, Liao L and $\mathrm{Xu}$ J. Phosphorylation of serine 68 of Twist1 by MAPKs stabilizes Twist1 protein and promotes breast cancer cell invasiveness. Cancer Res. 2011; 71:3980-3990.

36. Munkacsy G, Abdul-Ghani R, Mihaly Z, Tegze B, Tchernitsa O, Surowiak P, Schafer R and Gyorffy B. PSMB7 is associated with anthracycline resistance and is a prognostic biomarker in breast cancer. Brit J Cancer. 2010; 102:361-368.

37. Lee GY, Haverty PM, Li L, Kljavin NM, Bourgon R, Lee J, Stern H, Modrusan Z, Seshagiri S, Zhang Z, Davis D, Stokoe D, Settleman J, de Sauvage FJ and Neve RM. Comparative oncogenomics identifies PSMB4 and SHMT2 as potential cancer driver genes. Cancer Res. 2014; 74:3114-3126.

38. Aghajanian C, Blessing JA, Darcy KM, Reid G, DeGeest K, Rubin SC, Mannel RS, Rotmensch J, Schilder RJ, Riordan W and Gynecologic Oncology G. A phase II evaluation of bortezomib in the treatment of recurrent platinum-sensitive ovarian or primary peritoneal cancer: a Gynecologic Oncology Group study. Gynecologic oncology. 2009; 115:215-220.

39. Engel RH, Brown JA, Von Roenn JH, O'Regan RM, Bergan R, Badve S, Rademaker A and Gradishar WJ. A phase II study of single agent bortezomib in patients with metastatic breast cancer: a single institution experience. Cancer investigation. 2007; 25:733-737.

40. Rosenberg JE, Halabi S, Sanford BL, Himelstein AL, Atkins JN, Hohl RJ, Millard F, Bajorin DF, Small EJ, Cancer and Leukemia Group B. Phase II study of bortezomib in patients with previously treated advanced urothelial tract transitional cell carcinoma: CALGB 90207. Ann Oncol. 2008; 19:946950.

41. Lee BH, Lee MJ, Park S, Oh DC, Elsasser S, Chen PC, Gartner C, Dimova N, Hanna J, Gygi SP, Wilson SM, King RW and Finley D. Enhancement of proteasome activity by a small-molecule inhibitor of USP14. Nature. 2010; 467:179184.

42. Tam WL, Lu H, Buikhuisen J, Soh BS, Lim E, Reinhardt F, Wu ZJ, Krall JA, Bierie B, Guo W, Chen X, Liu XS, Brown M, Lim B and Weinberg RA. Protein kinase C alpha is a central signaling node and therapeutic target for breast cancer stem cells. Cancer Cell. 2013; 24:347-364.

43. Dontu G, Abdallah WM, Foley JM, Jackson KW, Clarke MF, Kawamura MJ and Wicha MS. In vitro propagation and transcriptional profiling of human mammary stem/ progenitor cells. Genes Dev. 2003; 17:1253-1270.

44. Chang JT, Palanivel VR, Kinjyo I, Schambach F, Intlekofer AM, Banerjee A, Longworth SA, Vinup KE, Mrass P, Oliaro J, Killeen N, Orange JS, Russell SM, Weninger W and Reiner SL. Asymmetric T lymphocyte division in the initiation of adaptive immune responses. Science. 2007; 315:1687-1691.

45. Subramanian A, Tamayo P, Mootha VK, Mukherjee S, Ebert BL, Gillette MA, Paulovich A, Pomeroy SL, Golub TR, Lander ES and Mesirov JP. Gene set enrichment analysis: a knowledge-based approach for interpreting genome-wide expression profiles. Proc Natl Acad Sci U S A. $2005 ; 102: 15545-15550$.

46. Mootha VK, Lindgren CM, Eriksson KF, Subramanian A, Sihag S, Lehar J, Puigserver P, Carlsson E, Ridderstrale M, Laurila E, Houstis N, Daly MJ, Patterson N, Mesirov JP, Golub TR, Tamayo P, et al. PGC-1alpha-responsive genes involved in oxidative phosphorylation are coordinately downregulated in human diabetes. Nat Genet. 2003; 34:267273.

47. Finak G, Bertos N, Pepin F, Sadekova S, Souleimanova M, Zhao H, Chen H, Omeroglu G, Meterissian S, Omeroglu A, Hallett M and Park M. Stromal gene expression predicts clinical outcome in breast cancer. Nat Med. 2008; 14:518527. 